\title{
Changing Characteristics of Obese Children and Adolescents Entering Pediatric Lifestyle Intervention Programs in Germany over the Last 11 Years: An Adiposity Patients Registry Multicenter Analysis of 65,453 Children and Adolescents
}

\begin{abstract}
Barbara Bohn ${ }^{a}$ Susanna Wiegand ${ }^{b}$ Wieland Kiess $^{c}$ Thomas Reinehr ${ }^{d}$
Rainer Stachow ${ }^{\mathrm{e}}$ Johannes Oepen ${ }^{f}$ Helmut Langhofg

Thomas Hermann $^{\text {h }}$ Kurt Widhalm ${ }^{i}$ Martin Wabitsch ${ }^{j}$ Ines Gellhaus ${ }^{k}$

Reinhard Holl ${ }^{a}$ for the APV Initiative and the German Competence

Network Obesity

a University of Ulm, Institute of Epidemiology and Medical Biometry, ZIBMT, Ulm, Germany; ${ }^{b}$ Department of Pediatric Endocrinology and Diabetology, Charité University Medicine, Berlin, Germany; ' ${ }^{C}$ University Hospital for Children and Adolescents, University of Leipzig, Leipzig, Germany; ${ }^{d}$ Department of Pediatric Endocrinology, Diabetes and Nutrition Medicine, Vestische Children's Hospital; University of Witten/Herdecke, Datteln, Germany; especialized Clinic Sylt, Rehabilitation Clinic for Children and Adolescents, Westerland,

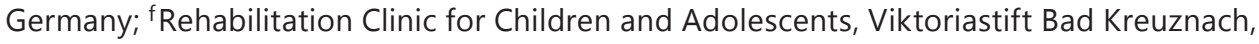
Bad Kreuznach, Germany; ${ }^{9}$ Clinic Schönsicht, Berchtesgaden, Germany; ${ }^{\text {h }}$ Specialized Rehabilitation Clinic Prinzregent Luitpold, Scheidegg/Allgäu, Germany; 'Division of Clinical Nutrition, Obesity and Lipid Disorders, Department of Pediatrics, Medical University of Vienna, Vienna, Austria; ${ }^{j}$ Division of Pediatric Endocrinology and Diabetes, University Hospital for Children and Adolescents, Ulm, Germany; ${ }^{k}$ Consensus Group Obesity Education for Children and Adolescents (KgAS), Paderborn, Germany
\end{abstract}

\section{Keywords}

Children · Adolescents · Obesity · Lifestyle intervention · Comorbidities · Inpatient care · Outpatient care $\cdot$ Time trends

\footnotetext{
Abstract migration background) were created for overweight, obesity, extreme obesity, and obesity-

Objective: To examine whether characteristics of children and adolescents who start lifestyle intervention (LI) for obesity in Germany changed over the last decade. Methods: 65,453 subjects (<21 years) from the APV database (Adiposity Patients Registry) with a BMI $\geq 90$ th percentile were included (years 2005-2015). Logistic regression models (confounders: age, sex, 
Bohn et al.: Changing Characteristics of Obese Children and Adolescents Entering Pediatric Lifestyle Intervention Programs in Germany over the Last 11 Years: An

Adiposity Patients Registry Multicenter Analysis of 65,453 Children and Adolescents

related comorbidities. Comorbidities were further adjusted for weight category. Results were stratified by inpatient or outpatient care. Results: Extreme obesity was found to be more frequent at the onset of LI (2005: 11.6; 2015: $12.7 \%)$ with a similar trend in subgroups ( $<0.001)$. Obesity increased (2005: 50.3\%; 2015: 55.1\%), and overweight decreased (2005: 34.1\%; 2015: $29.0 \%$ ) in the whole study population. Trends were similar for inpatient or outpatient care (all $\mathrm{p}<0.001$ ). Hypertension increased from $45.7 \%$ to $49.2 \%$ in the whole study population, and similar data were obtained in the subgroup of inpatients (both $p<0.0001$ ). Dyslipidemia increased in all patients (2005: 21.9\%; 2015: 28.0\%) and in inpatients (2005: 20.2\%; 2015: 25.7\%; both $\mathrm{p}<0.0001$ ). Abnormal carbohydrate metabolism rose in all patients (from 5.2 to $6.4 \%$; $p=0.0002$ ) without significant trends in subgroups. Conclusion: During the last decade, children and adolescents presented with higher BMI SDS at the onset of LI and the proportion with obesity-related comorbidities increased. Particularly the presence of comorbidities differed between outpatients and inpatients.

(C) 2017 The Author(s)

Published by S. Karger GmbH, Freiburg

\section{Introduction}

Based on the German Health Interview and Examination Survey for Children and Adolescents (KiGGS) $(n=17,641)$, it is estimated that $14.8 \%$ of children and adolescents $(2-17$ years of age) in Germany are overweight, including $6.1 \%$ obese subjects [1]. Overweight and obesity in children and adolescents can lead to serious health impairments [2]. Aside adverse emotional (e.g. depressive symptoms, low self-esteem) [3] and physical consequences (e.g. impaired balance, orthopedic problems) [2], there is an increased risk of cardiovascular disease [4] and type 2 diabetes [5, 6]. Studies also reported a high risk for tracking obesity and its associated metabolic changes from childhood to adulthood [7] which increases the risk of disease, disability, and premature death. Furthermore, it causes a high economic burden for the national health system $[8,9]$.

In Germany, several forms of lifestyle interventions (LI) for obesity are available in the outpatient as well as in the rehabilitation sector. In a study analyzing 1,916 children ( 8 to $<16$ years of age) from 48 institutions ( 5 rehabilitation, 43 outpatient centers) in Germany, the short-term success (1-year-follow-up) was as lower as more obese the children were [10]. The authors also stated a higher success rate in younger children [10]. Similar results were indicated by another study with 2-year follow-up [11]. This emphasizes the importance of an early and effective intervention in childhood obesity.

The utilization of behavior-based obesity therapy depends on motivation and acceptance in both patients and family [12], on the availability of LI [13] as well as on financing by health insurance or pension funds. All these determinants may change over time.

We examined whether characteristics of children and adolescents who start obesity treatments funded by statutory health insurance / pension funds in Germany changed over the last decade.

\section{Material and Methods}

\section{Patients and Data Documentation}

Data were provided by the Adiposity Patients Registry (APV), a standardized multicenter database for prospective documentation of anthropometric and metabolic parameters in overweight or obese children and adolescents. The APV is used by centers from Germany, Austria, and Switzerland specialized in obesity care for pediatric subjects. Anonymized data are transmitted from participating APV centers to Ulm, Germany, and aggregated into a cumulative database for clinical research and quality assurance $[14,15]$. Semi-annually, 
Fig. 1. Selection of study popula-

Bohn et al.: Changing Characteristics of Obese Children and Adolescents Entering Pediatric Lifestyle Intervention Programs in Germany over the Last 11 Years: An Adiposity Patients Registry Multicenter Analysis of 65,453 Children and Adolescents tion.

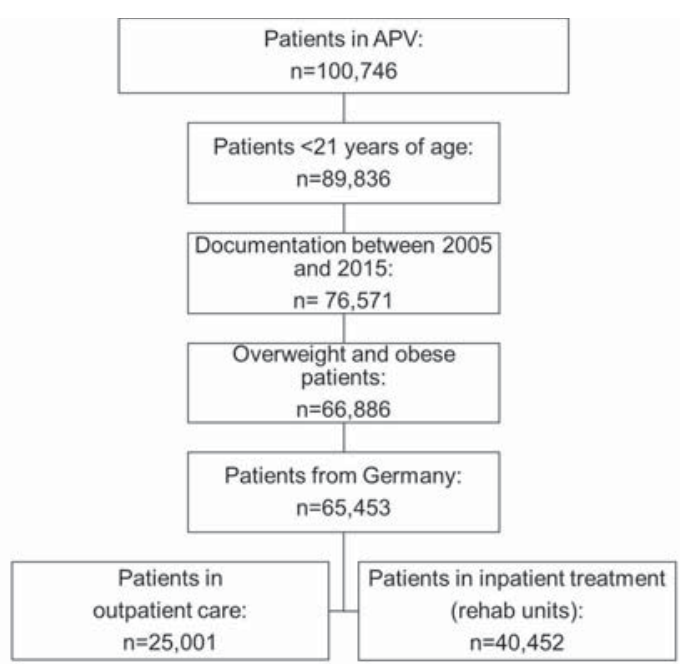

Table 1. Number of children and adolescents included in this analysis, stratified by treatment modality and calendar year

\begin{tabular}{lccccccccccc}
\hline & 2005 & 2006 & 2007 & 2008 & 2009 & 2010 & 2011 & 2012 & 2013 & 2014 & 2015 \\
\hline All & 5,890 & 6,234 & 6,202 & 6,517 & 6,561 & 6,763 & 5,932 & 6,083 & 5,812 & 5,263 & 4,196 \\
Outpatient & 1,625 & 1,764 & 1.922 & 2,323 & 2,561 & 2,718 & 2,812 & 2,619 & 2,378 & 2,256 & 2,023 \\
Inpatient & 4,265 & 4,470 & 4,280 & 4,194 & 4,000 & 4,045 & 3,120 & 3,464 & 3,434 & 3,007 & 2,173 \\
\hline
\end{tabular}

implausible and inconsistent data are reported back to the centers for verification or correction. The APV initiative is authorized by the Ethics Committee of the University of Ulm, Germany.

Until April 2016, 100,746 patients from 202 centers were registered in the APV. Overweight patients (BMI $\geq 90$ th percentile) under the age of 21 years and documentation between the years 2005 and 2015 were included in this analysis. Due to country-specific health systems and a low number of patients from Austria or Switzerland, only patients from Germany were included, resulting in 65,453 subjects from 182 centers (fig. 1). 25,001 children were treated in outpatient centers $(n=155)$ and 40,452 children in inpatient rehabilitation units $(\mathrm{n}=27)$. The number of included children and adolescents, stratified by treatment modality and calendar year, is illustrated in table 1.

\section{Anthropometric Measurements and Biochemical Parameters}

BMI was given as standard deviation score (SDS), using nationally representative reference values [16]. Overweight was defined as a BMI $\geq 90$ th to $<97$ th percentile, obesity as a BMI $\geq 97$ th to $<99.5$ th percentile, and extreme obesity as a BMI $\geq 99.5$ th percentile for age and sex [16]. To define hypertension, the 95th age- and sex-specific percentile of the KiGGS study was used [17]. Dyslipidemia was defined by at least one abnormal lipid value (total cholesterol (C) and LDL-C $>95$ th percentile, or HDL-C $<5$ th percentile [18]). Systolic and diastolic blood pressure as well as serum lipids were measured in local laboratories according to national guidelines [19]. An abnormal carbohydrate metabolism was defined as a fasting glucose level $\geq 100 \mathrm{mg} / \mathrm{dl}$ or 2-hour glucose level $\geq 140 \mathrm{mg} / \mathrm{dl}$ [20]. Additionally, the number of patients with at least one comorbidity was analyzed. For each patient, the records during the first month after their initial visit were analyzed.

\section{Statistical Analysis}

Descriptive statistics were implemented for the whole study population and separately for patients treated in rehabilitation or outpatient centers. Sociodemographic and clinical characteristics were presented as median (Q1; Q3) or as percentage. The percentage of patients with comorbidities refers to the number of 
Bohn et al.: Changing Characteristics of Obese Children and Adolescents Entering Pediatric Lifestyle Intervention Programs in Germany over the Last 11 Years: An

Adiposity Patients Registry Multicenter Analysis of 65,453 Children and Adolescents

Table 2. Overview of the completeness of information stratified by treatment modality and calendar year

\begin{tabular}{lccccccccccc}
\hline \multicolumn{2}{c}{2005} & 2006 & 2007 & 2008 & 2009 & 2010 & 2011 & 2012 & 2013 & 2014 & 2015 \\
\hline $\begin{array}{l}\text { Hypertension } \\
\text { All }\end{array}$ & $78.0 \%$ & $83.5 \%$ & $87.3 \%$ & $83.3 \%$ & $86.6 \%$ & $87.2 \%$ & $84.0 \%$ & $77.1 \%$ & $71.1 \%$ & $67.9 \%$ & $83.7 \%$ \\
Outpatient & $70.0 \%$ & $73.4 \%$ & $77.2 \%$ & $76.5 \%$ & $75.2 \%$ & $77.5 \%$ & $79.6 \%$ & $77.9 \%$ & $79.2 \%$ & $78.4 \%$ & $79.0 \%$ \\
Inpatient & $81.0 \%$ & $87.4 \%$ & $91.9 \%$ & $87.0 \%$ & $93.9 \%$ & $93.7 \%$ & $88.0 \%$ & $76.4 \%$ & $65.5 \%$ & $60.0 \%$ & $88.0 \%$ \\
\hline $\begin{array}{l}\text { Dyslipidemia } \\
\text { All }\end{array}$ & $60.1 \%$ & $68.9 \%$ & $69.5 \%$ & $67.5 \%$ & $66.0 \%$ & $68.6 \%$ & $60.0 \%$ & $53.9 \%$ & $59.7 \%$ & $59.3 \%$ & $69.0 \%$ \\
Outpatient & $58.6 \%$ & $66.5 \%$ & $75.9 \%$ & $64.8 \%$ & $56.6 \%$ & $62.0 \%$ & $58.0 \%$ & $58.9 \%$ & $62.8 \%$ & $62.8 \%$ & $63.6 \%$ \\
Inpatient & $60.7 \%$ & $69.8 \%$ & $66.6 \%$ & $69.1 \%$ & $72.0 \%$ & $73.1 \%$ & $61.8 \%$ & $50.1 \%$ & $57.5 \%$ & $56.7 \%$ & $74.0 \%$ \\
\hline Abnormal carbohydrate metabolism & & & & & & & & \\
All & $49.9 \%$ & $60.1 \%$ & $59.8 \%$ & $61.5 \%$ & $62.8 \%$ & $62.1 \%$ & $53.5 \%$ & $46.3 \%$ & $49.2 \%$ & $49.8 \%$ & $61.9 \%$ \\
$\begin{array}{l}\text { Outpatient } \\
\text { Inpatient }\end{array}$ & $43.5 \%$ & $56.3 \%$ & $63.9 \%$ & $54.5 \%$ & $44.9 \%$ & $50.2 \%$ & $44.1 \%$ & $43.3 \%$ & $45.9 \%$ & $46.7 \%$ & $52.3 \%$ \\
\hline
\end{tabular}

patients with documented examinations, and not to the total number of subjects per calendar year. An overview of the completeness of information stratified by treatment modality and calendar year is given in table 2 . To compare differences between patients from outpatient and rehabilitation care, chi-square test was used for dichotomous variables, and Kruskal-Wallis test for continuous variables. The false discovery rate was applied to correct $\mathrm{p}$ values for multiple comparisons.

Logistic regression models, adjusted for age, sex, and migration background (the child or at least one parent was born outside of Germany) were applied for dichotomous variables (weight categories, hypertension, dyslipidemia, abnormal carbohydrate metabolism, and proportion with at least one comorbidity). Logistic models for comorbidities were additionally adjusted for weight category.

Results of regression models were given for the whole study population and separately for rehabilitation and outpatient care. Moreover, analyses were conducted to identify different trends in age groups $[<11$ years / $\geq 11$ years) or according to gender. The number of patients with at least one comorbidity was further stratified by weight category. Adjusted estimates of each year (2005-2015) based on the overall model were calculated. P values for trend were calculated with calendar year as continuous variable.

A two-sided p value $<0.05$ was considered significant. All statistical analyses were implemented with SAS 9.4 (Statistical Analysis Software; SAS Institute, Cary, NC, USA).

\section{Results}

\section{Study Population}

The final study population comprised 65,453 children and adolescents $\left(\mathrm{n}_{\text {outpatient }}=\right.$ 25,$001 ; n_{\text {inpatient }}=40,452$ ). At the onset of LI, $34.2 \%$ were overweight, $52.3 \%$ obese, and $13.5 \%$ extremely obese (table 3 ). Unadjusted data indicated a higher proportion of extremely obese children and adolescents in outpatient centers compared to inpatient centers (14.6\% vs. $12.8 \% ; \mathrm{p}<0.0001)$. In the whole study population, hypertension was most frequent (47.6\%), followed by dyslipidemia (25.1\%), and an abnormal carbohydrate metabolism (6.6\%). Obesity-related comorbidities were more frequent in children treated in outpatient centers compared to those treated in rehabilitation centers $(p<0.05)$. More information on the study population and on differences between patients are summarized in table 3 .

Weight Category - Time Trends

Logistic regression revealed an increase of patients classified as obese $(\geq 97$ th to $<99.5$ th percentile) from $50.3 \%$ in 2005 to $55.1 \%$ in 2015 ( $<<0.0001$ ) in the whole study population. 
Bohn et al.: Changing Characteristics of Obese Children and Adolescents Entering Pediatric Lifestyle Intervention Programs in Germany over the Last 11 Years: An Adiposity Patients Registry Multicenter Analysis of 65,453 Children and Adolescents

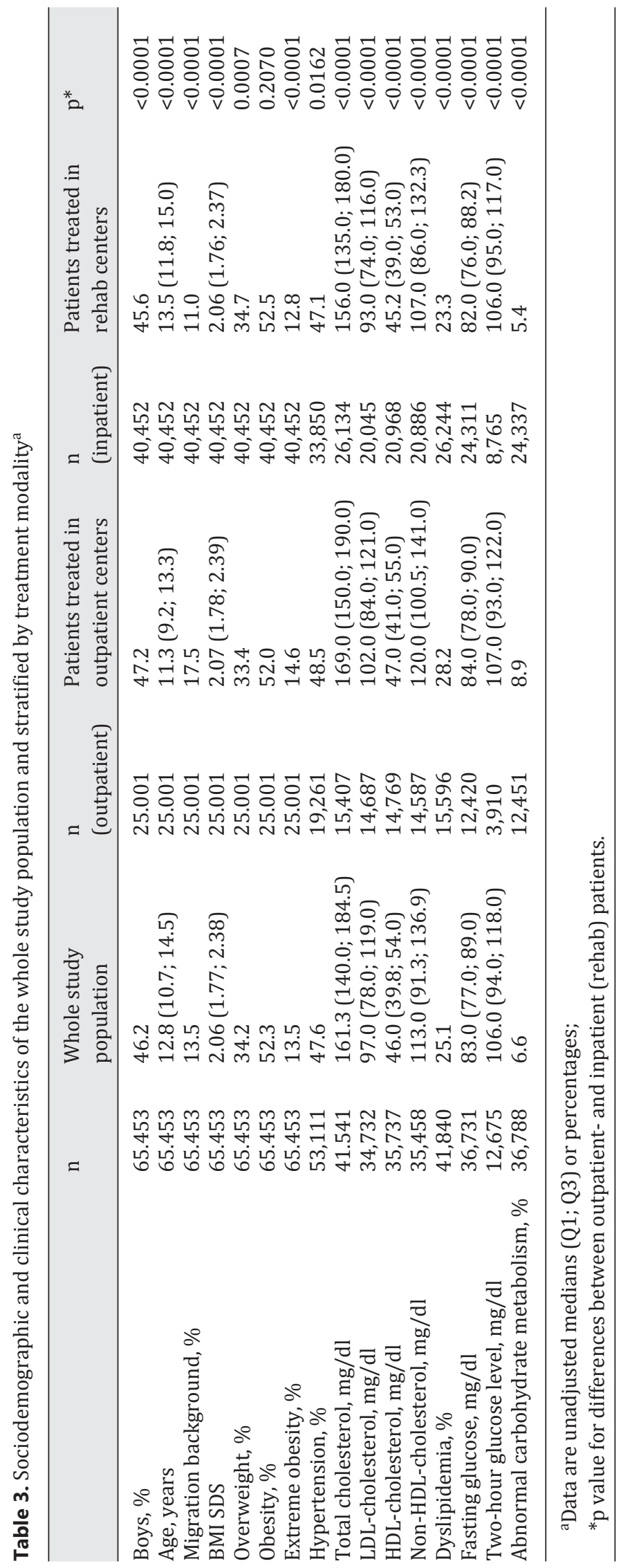


Bohn et al.: Changing Characteristics of Obese Children and Adolescents Entering Pediatric Lifestyle Intervention Programs in Germany over the Last 11 Years: An Adiposity Patients Registry Multicenter Analysis of 65,453 Children and Adolescents

Fig. 2. Trends in a overweight, b obesity, and c extreme obesity in the whole study population and stratified for outpatient or rehabilitation center between the years 2005 and 2015 (data adjusted for age, sex, and migration background).

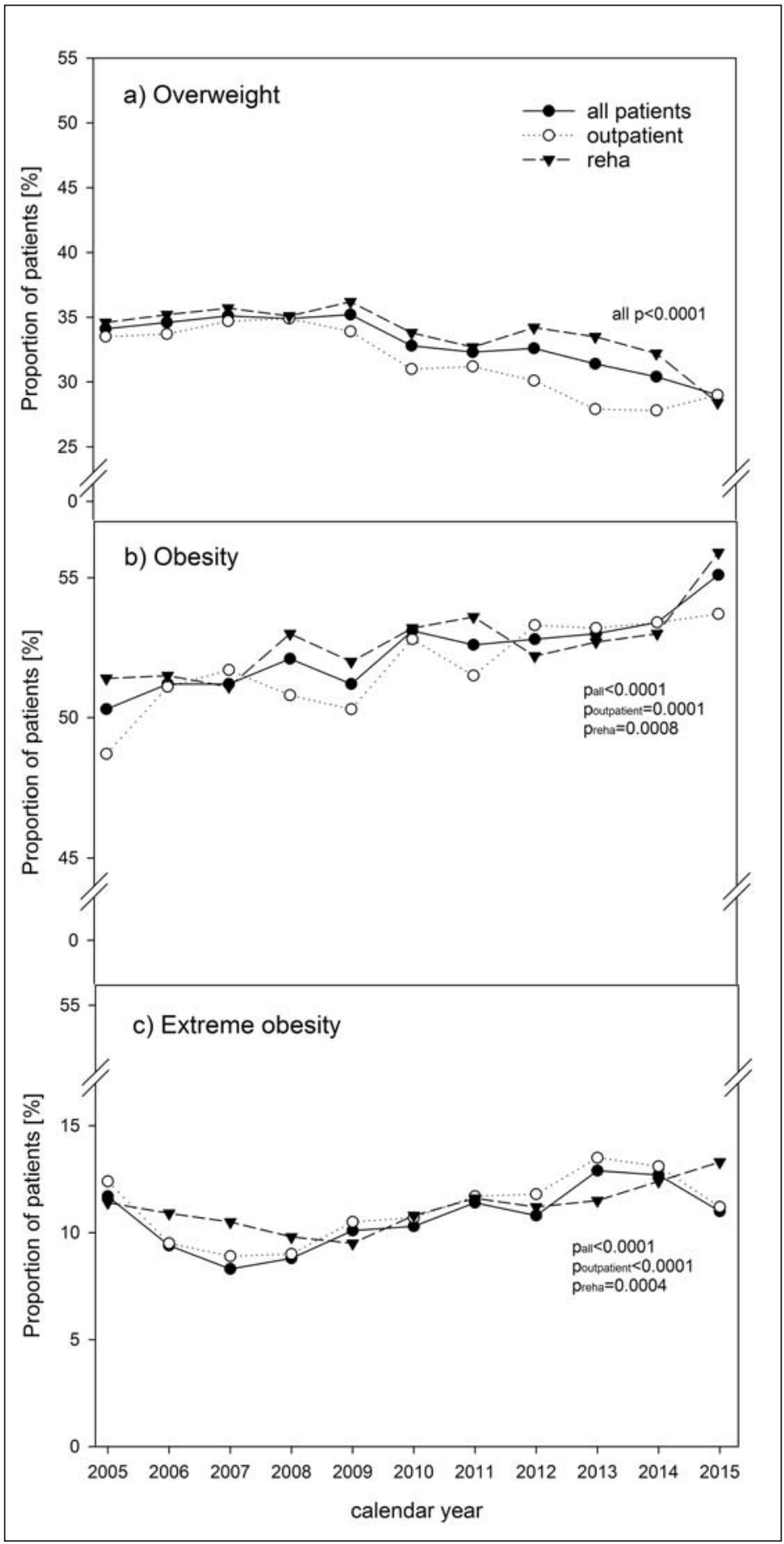

This trend was present in both subgroups (fig. $2 b)\left(p_{\text {outpatient }}=0.0001 ; p_{\text {rehabilitation }}=0.0008\right)$. The prevalence of extreme obesity ( $\geq 99$.5th percentile) at the beginning of a LI initially decreased in the whole study population from $11.6 \%$ in 2005 to $9.3 \%$ in 2008 and then increased again to $12.7 \%$ in 2015 ( $\mathrm{p}<0.0001)$. A similar trend was observed in both subgroups $\left(p_{\text {outpatient }}<0.0001 ; p_{\text {rehabilitation }}=0.0004\right.$.) (fig. 2 c). Overweight prevalence $(\geq 90$ th to $<97$ th percentile) decreased in the whole study population from $34.1 \%$ in 2005 to $29.0 \%$ in 2015 
Bohn et al.: Changing Characteristics of Obese Children and Adolescents Entering Pediatric Lifestyle Intervention Programs in Germany over the Last 11 Years: An Adiposity Patients Registry Multicenter Analysis of 65,453 Children and Adolescents

Fig. 3. Trends in a hypertension,

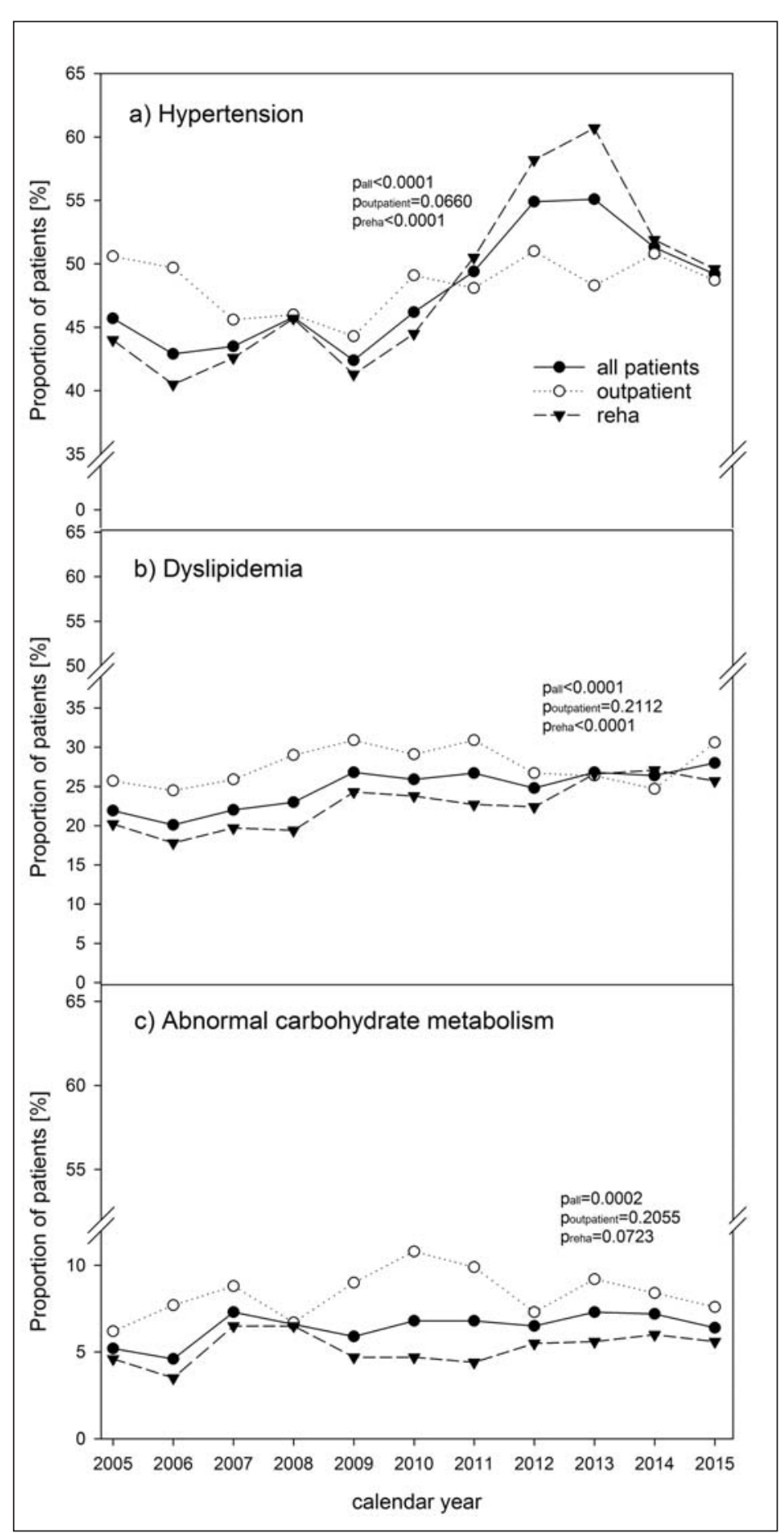
b dyslipidemia, and c abnormal carbohydrate metabolism in the whole study population and stratified for outpatient or rehabilitation center between the years 2005 and 2015 (data adjusted for sex, age, weight category, and migration background).

$(\mathrm{p}<0.0001)$. A decline was seen in patients from outpatient as well as from rehabilitation centers (both $\mathrm{p}<0.001$ ) (fig. 2a).

\section{Trends for Obesity-Related Comorbidities}

Findings from logistic regression models for trends in the prevalence of obesity-related comorbidities at the beginning of LI, adjusted for demographics and weight category, are 
Bohn et al.: Changing Characteristics of Obese Children and Adolescents Entering Pediatric Lifestyle Intervention Programs in Germany over the Last 11 Years: An Adiposity Patients Registry Multicenter Analysis of 65,453 Children and Adolescents

shown in figure 3. The proportion of children and adolescents with hypertension increased from $45.7 \%$ in 2005 to $55.1 \%$ in 2013 and then decreased again to $49.2 \%$ in 2015 ( $<<0.0001$ ). In outpatient-treated subjects, prevalence decreased from $50.6 \%$ in 2005 to $44.3 \%$ in 2009 and then increased to almost 50\% in 2015 ( $\mathrm{p}=0.0660)$. The number of inpatient-treated patients with hypertension increased from $44.0 \%$ in 2005 to $60.9 \%$ in 2013 and then declined to $49.6 \%$ in $2015(\mathrm{p}<0.0001)$ (fig. 3a). Dyslipidemia increased in the whole study population from $21.9 \%$ to $28.0 \%$ and from $20.2 \%$ to $25.7 \%$ in rehabilitation-treated patients (both $\mathrm{p}<$ 0.0001). In outpatient-treated patients, no significant trend was present ( $p=0.2112$ ) (fig. $3 b)$. Children and adolescents with an abnormal carbohydrate metabolism became more frequent during the last decade (from $5.2 \%$ to $6.4 \% ; \mathrm{p}=0.0002$ ). No significant trend was found in patients from inpatient or outpatient centers $\left(\mathrm{p}_{\text {outpatient }}=0.2055 ; \mathrm{p}_{\text {rehabilitation }}=0.0723\right.$ ) (fig. 3c).

\section{Number and Trends of Patients with at Least One Comorbidity}

$56.2 \%$ of the whole study population had at least one comorbidity. Stratified by weight category, the proportion was lowest in overweight patients $(46.3 \%)$, followed by obese (59.9\%) and extremely obese patients (66.0\%). The number of overweight and obese subjects with at least one comorbidity was higher in outpatient compared to inpatient centers $(49.2 \%$ vs. $44.7 \%$; $62.2 \%$ vs. $58.6 \%$ ). In extremely obese patients, a higher comorbidity prevalence was found in patients from rehabilitation units (68.8\% vs. $61.8 \%)$.

The logistic regression model revealed an increase of patients with at least one comorbidity from $53.1 \%$ to $60.0 \%$ in the whole study population, and from $50.9 \%$ to $59.9 \%$ in inpatient centers (both $\mathrm{p}<0.0001)$. The increase in outpatients was negligible $(59.3 \%$ to $59.8 \%$; $\mathrm{p}=0.2883$ ). Stratified by weight category (fig. $4 \mathrm{a}-\mathrm{c}$ ), a rise was observed in overweight (from $40.0 \%$ in 2005 to $50.9 \%$ in 2015) and in obese patients (from $57.8 \%$ to $62.4 \%$; both p < $0.0001)$, but not in extremely obese subjects $(69.6 \%$ vs. $71.0 \% ; p=0.0533)$. These trends were also valid when focusing on inpatient centers, but not when only outpatients were analyzed (fig. $4 \mathrm{a}-\mathrm{c}$ ).

\section{Trends for Weight Category and Comorbidities Stratified by Gender}

Regression analysis revealed an increase of obese subjects starting LI in boys (from $51.5 \%$ to $55.8 \%$; $p=0.0002$ ) as well as in girls (from $49.2 \%$ to $54.5 \%$; $=0.0022$ ). The number of extremely obese patients initially decreased, and then increased until the year 2015. This trend was present in both sexes (boys: $12.2 \%$ (2005), 10.1\% (2008), 13.8\% (2015), p < 0.0001); girls: $11.2 \%$ (2005), 8.6\% (2009), $11.2 \%$ (2015), $p=0.0004)$. The proportion of overweight children and adolescents decreased in boys from $32.7 \%$ to $27.1 \%$ and in girls from $35.4 \%$ to $30.6 \%$ (both $\mathrm{p}<0.0001$ ).

Similar to the results for the whole study population (fig. 3a), hypertension increased during the first years and then decreased again. This pattern was present in boys $(46.9 \%$ (2005), 56.4\% (2012), 51.3\% (2015); p < 0.0001) and in girls (44.7\% (2005), 54.3\% (2013), $46.8 \%$ (2015); $\mathrm{p}<0.0001)$. Dyslipidemia became more frequent in boys (23.3\% vs. $32.1 \%)$, and in girls (20.6\% vs. $24.9 \%$; $<<0.0001)$. The proportion with an abnormal carbohydrate metabolism slightly increased in both sexes (boys: $4.9 \%$ vs. $6.6 \%$; $p=0.0041$ / girls: $5.4 \%$ vs. $6.2 \% ; \mathrm{p}=0.0506$ ). The number of patients with at least one comorbidity increased from $54.4 \%$ to $63.1 \%$ in boys, and from $52.0 \%$ to $56.6 \%$ in girls (both $\mathrm{p}<0.0001$ ).

\section{Trends for Weight Category and Comorbidities Stratified by Age Group}

In the younger children ( $<11$ years of age), the number of obese children at the onset of LI increased non-significantly from $45.4 \%$ to $52.8 \%$ ( $p=0.0774$ ). In subjects $\geq 11$ years of age, the proportion increased from $52.4 \%$ to $55.7 \%$ ( $p<0.0001$ ). Extreme obesity became more 
Bohn et al.: Changing Characteristics of Obese Children and Adolescents Entering Pediatric Lifestyle Intervention Programs in Germany over the Last 11 Years: An Adiposity Patients Registry Multicenter Analysis of 65,453 Children and Adolescents

Fig. 4. Trends in the number of

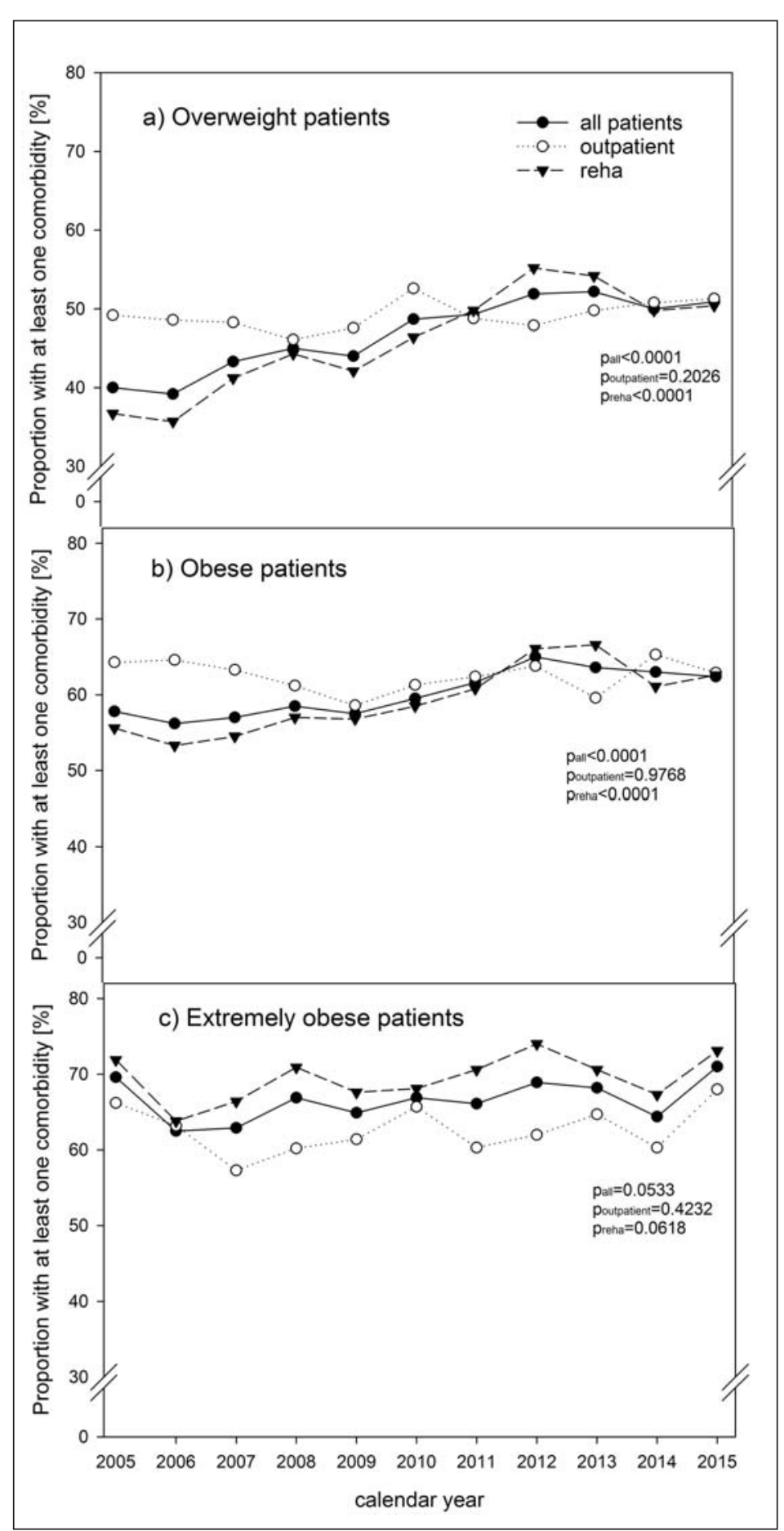
patients with at least one comorbidity in a overweight, b obese, and c extremely obese patients in the whole study population and stratified for outpatient or rehabilitation center between the years 2005 and 2015 (data adjusted for sex, age, and migration background).

frequent in both age groups ( $<11$ years: $22.6 \%$ vs. $23.7 \%$; $\geq 11$ years: $10.0 \%$ vs. $12.8 \%$; $p<$ 0.0001 ). Overweight decreased in children $<11$ years of age from $30.8 \%$ to $23.2 \%$, and in $\geq 11$-year-olds from $37.3 \%$ to $31.7 \%$ (both $\mathrm{p}<0.0001$ ).

The prevalence of hypertension initially increased and then declined in both age groups (<11 years: 44.8\% (2005), 48.9\% (2012), 46.7\% (2015); $\geq 11$ years: $46.8 \%$ (2005), 57.7\% (2012), 49.8\% (2015); $\mathrm{p}<0.0001$ ). The proportion of <11-yea-olds with dyslipidemia 
Bohn et al.: Changing Characteristics of Obese Children and Adolescents Entering Pediatric Lifestyle Intervention Programs in Germany over the Last 11 Years: An

Adiposity Patients Registry Multicenter Analysis of 65,453 Children and Adolescents

Table 4. German reimbursement criteria for outpatient LI in overweight/obese children [22]

\begin{tabular}{llll}
\hline BMI & No risk factors & Risk factors* & Disease** \\
\hline >99.5 percentile & yes & yes & yes \\
$>97$. to $<99.5$ percentile & no & yes & yes \\
$>90$. to 97 . percentile & no & no & yes \\
\hline
\end{tabular}

*Insulin resistance, dyslipidemia, familial predisposition (type 2 diabetes in parents, myocardial infarction or stroke before the age of 55, 1. and 2. degree of relationship).

** Arterial hypertension, type 2 diabetes, abnormal glucose metabolism, premature pubertal development, polycystic ovary syndrome, orthopedic illnesses.

increased from $23.8 \%$ to $26.1 \%$ ( $\mathrm{p}=0.0053$ ) and from $22.0 \%$ to $29.0 \%$ in $\geq 11$-year-olds ( $\mathrm{p}<$ $0.0001)$. A non-significant decline in the number of children with an abnormal carbohydrate metabolism was found in $<11$-year-olds ( $5.0 \%$ vs. $4.2 \%$; $\mathrm{p}=0.8513)$, whereas in subjects $\geq 11$ years of age, this comorbidity became more frequent $(5.4 \%$ vs. $7.1 \%$; p < 0.0001). The percentage of children and adolescents with at least one comorbidity showed a higher increase over time in older children ( $\geq 11$ years: $54.0 \%$ vs. $61.8 \%$; $p<0.0001$ ) than in younger ones ( $<11$ years: $53.1 \%$ vs. $53.8 \%$; $p=0.0016)$.

\section{Discussion}

The present analysis shows significant changes in patient's characteristics at the onset of LI for obesity over the last 11 years. Furthermore, different trends were detected for patients treated as outpatients or inpatients, as well as for age groups or gender.

During the last decade, the proportion of overweight children and adolescents at the beginning of LI decreased, whereas the number of obese patients increased. The trend in patients with extreme obesity is less clear (fig. $2 \mathrm{a}-\mathrm{c}$ ). Previous studies indicated that a lower BMI at the beginning of a LI is one predictor of success as measured by BMI SDS $[10,11]$. However, the indication to participate in an outpatient or inpatient LI depends on obesity degree and existing risk factors or comorbidities (table 4) [21,22]. According to these criteria, a LI is only indicated in overweight children and adolescents with at least one additional comorbidity. This applies to $46.3 \%$ of our study population. Overall, the most common comorbidity was hypertension (2015: 49.2\%), followed by dyslipidemia (2015: 28.0\%), and an abnormal carbohydrate metabolism (2015: 6.4\%). In our study population, the percentage of subjects with an abnormal carbohydrate metabolism is (of unknown reasons) lower compared to, e.g., that of the Swedish childhood obesity treatment registry BORIS showing a prevalence of $17.1 \%$ [5]. In contrast to other studies, the prevalence of hypertension in our study population is high $[23,24]$. This can be explained by the high percentage of obese and extremely obese patients, and the use of KiGGS reference values for definition of hypertension [25].

The number of patients with at least one comorbidity increased by weight category (46.3\% vs. $59.9 \%$ vs. $66.0 \%$ ). The differences are in line with results of the Swedish BORIS or the American POWER (Pediatric Obesity Weight Evaluation Registry) registries indicating an association between the degree of obesity and a higher risk of cardiovascular risk $[5,26]$. Over the last decade, the proportion of patients with overweight or obesity and at least one comorbidity at the beginning of LI increased (fig. $4 a-c)$. In extremely obese patients, the percentage remained on a constantly high level. One reason for the increment could be that German health insurance is more rigorous in reimbursement decisions. It is also possible that 
Bohn et al.: Changing Characteristics of Obese Children and Adolescents Entering Pediatric Lifestyle Intervention Programs in Germany over the Last 11 Years: An Adiposity Patients Registry Multicenter Analysis of 65,453 Children and Adolescents

parents and their children decide to participate in LI at a later stage. Moreover, the number of APV centers differs in the course of the observation period and more centers with higherrisk patients may participate in the APV initiative during recent years.

Stratified by outpatient or inpatient treatment, dyslipidemia and an abnormal carbohydrate metabolism were more frequently found in outpatient centers. This remains stable between the years 2005 and 2015 (fig. 3b-c). Considering patients with at least one comorbidity stratified by weight category, the proportion of overweight or obese patients with at least one comorbidity was higher in outpatient compared to inpatient centers $(49.2 \% \mathrm{vs}$. $44.7 \%$ and $62.2 \%$ vs. $58.6 \%$ ). In extremely obese patients, inverse results were found $(61.8 \%$ vs. $68.8 \%$ ). Regarding changes over time, the number of overweight or obese patients with at least one comorbidity increased in inpatient, but not in outpatient centers (fig. 4a-c).

In Germany, reimbursement for a LI in outpatient or inpatient centers is very different. Outpatient LI for obesity can be covered by statutory health insurance [27]. In the year 2004, a consensus paper was developed that should facilitate the assessment of treatment programs and provide orientation for reimbursement [28]. The decision depends on medical, mental, and social conditions, and training programs need to meet several evaluation criteria comprising concept quality as well as structure, process, and outcome quality $[21,22,28]$. The fulfilment of those criteria is a precondition for potential reimbursement by statutory health insurances. Moreover, the efficacy and efficiency of training programs have to be demonstrated. Several systematic reviews indicated a beneficial effect of training programs on BMI. However, due to unexplained heterogeneity of studies included and potential study bias, results have to be interpreted cautiously [29-31]. Despite the necessity to proof sustainable improvements, the willingness to finance such analysis appears to be limited. Therefore, studies examining the long-term effects of German training programs are still scarce, and thus financing of a LI remains difficult. A statement of the National Association of Statutory Health Insurance Funds for an updated version of the consensus paper was published in 2015 [32]. According to these recommendations, indication to participate in a LI for overweight or obese children and adolescents should only be given after an unsuccessful treatment by a pediatrician according to current guidelines $[21,32]$. The financing of inpatient rehabilitation treatment is usually covered by pension funds [33]. Similar to the outpatient sector, the reimbursement depends on personal characteristics (e.g. sufficient physical and mental resilience), and on the quality of the rehabilitation units [34]. Apart from the financing system, differences in the completeness of information on comorbidities (table 2) could be attributed to the differences between outpatients and inpatients. Large differences and fluctuations during the last 11 years could be observed in both within a particular treatment modality as well as between treatment modalities. For example in 2009, information on blood pressure was available for $93.9 \%$ of inpatient-treated subjects but only for $75.2 \%$ of the outpatients. In contrast, in 2014 , the completeness was lower in inpatients $(60.0 \%)$ compared to outpatients (78.4\%). Regarding the last 11 years, the number of documented inpatient-treated children and adolescents decreased, whereas the number of outpatient-treated patients increased in the APV database (table 1). Especially, trends in the number of patients with at least one comorbidity differed between outpatient and inpatient subjects. Whereas in inpatients, an increase was observed, no trend was indicated in outpatients (fig. 4a-b). Possibly, the number of inpatient-treated subjects became lower but those treatment-seeking patients have a worse cardiovascular risk profile.

We further identified differences in gender and age groups ( $<11$ years vs. $\geq 11$ years). Although the overall trends are comparable in gender or age groups, we found differences in the absolute frequencies. At the onset of a LI, boys were more frequently classified as obese or extremely obese compared to girls, and comorbidities were more prevalent. A review indicated that body satisfaction and well-being is more reduced in obese girls compared to boys 
Bohn et al.: Changing Characteristics of Obese Children and Adolescents Entering Pediatric Lifestyle Intervention Programs in Germany over the Last 11 Years: An Adiposity Patients Registry Multicenter Analysis of 65,453 Children and Adolescents

and that obese females are more disliked and negatively rated by their peers compared to obese males [35]. Maybe, the higher social pressure could be one explanation for the earlier onset of LI in girls. Regarding age groups, a higher prevalence of extreme obesity at the beginning of a LI was present in the younger ( $<11$ years of age) compared to the older children ( $\geq 11$ years of age) (year 2015: $23.7 \%$ vs. $12.8 \%$ ). In contrast, comorbidities were more frequently documented in patients $\geq 11$ years of age. The higher prevalence of obesity-related comorbidities can be partly explained by a longer duration of overweight/obesity in older children which is associated with a higher risk for hypertension or dyslipidemia [36].

\section{Strengths and Limitations}

The study benefits from the large number of patients and the multicenter design. Another strength is the application of the same documentation software since 2005. Furthermore, detailed information on patients is documented in the APV to control for potential confounders. However, due to the multicenter nature of data collection, variability in the measurements of BMI as well as of biochemical parameters cannot be excluded despite standardized procedures. Another limiting factor could be that in $90 \%$ of the patients, blood pressure and laboratory data are measure only once. This might have resulted in e.g. somewhat higher values of blood pressure, also known as 'white coat effect'. Moreover, it is unclear whether or not serum lipids were determined under fasting conditions. Furthermore, some clinical characteristics were not completely documented in all patients, and completeness also differs between treatment modalities. Another limitation is that the number of participating centers varies between the years. Therefore, a selection bias could be possible.

\section{Conclusion}

The number of obese children and adolescents starting a LI increased, and the proportion of patients with obesity-related comorbidities became higher. Therefore, more patients with unfavorable prospects of success started therapy during recent years, reflecting later instead of earlier structured LI. Boys were more obese and had a higher prevalence of comorbidities at the onset of a LI compared to girls. In younger children, extreme obesity was more frequent and comorbidities less frequent compared to older children. Especially trends regarding the presence of at least one comorbidity differed between outpatient and inpatient treatment centers. This can be partly explained by different financing systems or a switch in available treatment options.

\section{Acknowledgements}

We thank E. Bollow for statistical analysis. Furthermore, we thank all participating centers of the APV initiative, especially the collaborating centers.

\section{Funding}

The study was supported by the German Competence Network Obesity funded by the Federal Ministry of Education and Research (FKZ 01GI1130) (expired at the beginning of 2016). Further financial support was provided by the German Diabetes Association (DDG). Sponsors were not involved in data acquisition or analysis.

\section{Disclosure Statement}

The authors report no conflicts of interest. 
Bohn et al.: Changing Characteristics of Obese Children and Adolescents Entering Pediatric Lifestyle Intervention Programs in Germany over the Last 11 Years: An Adiposity Patients Registry Multicenter Analysis of 65,453 Children and Adolescents

\section{References}

1 Kurth BM, Schaffrath Rosario A: Overweight and obesity in children and adolescents in Germany (in German). Bundesgesundheitsbl Gesundheitsforsch Gesundheitsschutz 2010;53:643--652.

2 Liverman CT, Koplan J, Kraak VI: Extent and consequences of childhood obesity; in Liverman CT, Koplan J, Kraak VI (eds): Preventing Childhood Obesity: Health in the Balance. Washington, D.C, National Academies Press, 2005, pp 54-78.

-3 Wille N, Bullinger M, Holl R, Hoffmeister U, Mann R, Goldapp C, Reinehr T, Westenhöfer J, Egmond-Froehlich A, Ravens-Sieberer U: Health-related quality of life in overweight and obese youths: Results of a multicenter study. Health Qual Life Outcomes 2010;8:36.

4 I'Allemand D, Wiegand S, Reinehr T, Müller J, Wabitsch M, Widhalm K, Holl R: Cardiovascular risk in 26,008 European overweight children as established by a multicenter database. Obesity (Silver Spring) 2008;16: 1672-1679.

-5 Hagman E, Reinehr T, Kowalski J, Ekbom A, Marcus C, Holl RW: Impaired fasting glucose prevalence in two nationwide cohorts of obese children and adolescents. Int J Obes Relat Metab Disord 2014;38:40-45.

6 Reinehr T: Type 2 diabetes mellitus in children and adolescents. World J Diabetes 2013;4:270.

7 Singh AS, Mulder C, Twisk JWR, van Mechelen W, Chinapaw MJM: Tracking of childhood overweight into adulthood: a systematic review of the literature. Obes Rev 2008;9:474-488.

-8 Baker JL, Olsen LW, Sørensen TIA: Childhood body-mass index and the risk of coronary heart disease in adulthood. N Engl J Med 2007;357:2329-2337.

-9 Sonntag D, Ali S, Lehnert T, Konnopka A, Riedel-Heller S, König HH: Estimating the lifetime cost of childhood obesity in Germany: Results of a Markov Model. Pediatr Obes 2015;10:416-422.

10 Hoffmeister U, Bullinger M, van Egmond-Fröhlich A, Goldapp C, Mann R, Ravens-Sieberer U, Reinehr T, Westenhöfer J, Wille N, Holl RW: Overweight and obesity in childhood and adolescence: Evaluation of inpatient and outpatient care in Germany: the EvAKuJ study (in German). Bundesgesundheitsbl Gesundheitsforsch Gesundheitsschutz 2011;54:128-135.

11 Wiegand S, Keller KM, Lob-Corzilius T, Pott W, Reinehr T, Röbl M, Stachow R, Tuschy S, Weidanz I, Widhalm K, de Zwaan M, Holl RW: Predicting weight loss and maintenance in overweight/obese pediatric patients. Horm Res Paediatr 2014;82:380-387.

12 Gunnarsdottir T, Njardvik U, Olafsdottir AS, Craighead LW, Bjarnason R: The role of parental motivation in family-based treatment for childhood obesity. Obesity (Silver Spring) 2011;19:1654-1662.

13 Rattay P, Starker A, Domanska O, Butschalowsky H, Gutsche J, Kamtsiuris P: Trends in the utilization of outpatient medical care in childhood and adolescence (in German). Bundesgesundheitsbl Gesundheitsforsch Gesundheitsschutz 2014;57:878-891.

14 Bohn B, Müller MJ, Simic-Schleicher G, Kiess W, Siegfried W, Oelert M, Tuschy S, Berghem S, Holl RW: BMI or BIA: Is body mass index or body fat mass a better predictor of cardiovascular risk in overweight or obese children and adolescents? A German/Austrian/Swiss multicenter APV analysis of 3,327 children and adolescents. Obes Facts 2015;8:156-165.

15 Martin L, Oepen J, Reinehr T, Wabitsch M, Claussnitzer G, Waldeck E, Ingrisch S, Stachow R, Oelert M, Wiegand S, Holl R: Ethnicity and cardiovascular risk factors: evaluation of 40,921 normal-weight, overweight or obese children and adolescents living in Central Europe. Int J Obes (Lond) 2015;39:45-51.

16 Schaffrath Rosario A, Kurth B, Stolzenberg H, Ellert U, Neuhauser H: Body mass index percentiles for children and adolescents in Germany based on a nationally representative sample (KiGGS 2003-2006). Eur J Clin Nutr 2010;64:341-349.

17 Neuhauser HK, Thamm M, Ellert U, Hense HW, Schaffrath Rosario A: Blood pressure percentiles by age and height from nonoverweight children and adolescents in Germany. Pediatrics 2011;127:e978-88.

18 Thierfelder W, Dortschy R, Hintzpeter B, Kahl H, Scheidt-Nave C: Biochemical measures in the German Health Interview and Examination Survey for Children and Adolescents (KiGGS) (in German). Bundesgesundheitsbl Gesundheitsforsch Gesundheitsschutz 2007;50:757-770.

19 Bundesärztekammer (BÄK) Arbeitsgemeinschaft der Deutschen Ärztekammern: Richtlinie der Bundesärztekammer zur Qualitätssicherung laboratoriumsmedizinischer Untersuchungen (Rili-BÄK). Dtsch Arztebl 2014;111:A1583-A1618.

20 Craig ME, Jefferies C, Dabelea D, Balde N, Seth A, Donaghue KC: ISPAD clinical practice consensus guidelines 2014. Definition, epidemiology, and classification of diabetes in children and adolescents. Pediatr Diabetes 2014;15(suppl 20):4-17.

21 Wabitsch M, federführend für die AGA: Konsensbasierte (S2) Leitlinie zur Diagnostik, Therapie und Prävention von Übergewicht und Adipositas im Kindes- und Jugendalter: Version 15.10.2015. www.adipositas-gesellschaft.de/fileadmin/PDF/Leitlinien/AGA_S2_Leitlinie.pdf (last accessed October 5, 2017).

22 Bundeszentrale für Gesundheitliche Aufklärung: Qualitätskriterien für Programme zur Prävention und Therapie von Übergewicht und Adipositas bei Kindern und Jugendlichen, Aufl.: 2. 10.10.06. Gesundheitsförderung konkret. Köln, Bundeszentrale für Gesundheitliche Aufklärung. www.bzga.de/botmed_60644000.html (last accessed October 5, 2017).

-23 Tepe D, Demirel F, Seker ED, Arhan EP, Tayfun M, Esen I, Kara O, Kizilgun M: Prevalence of idiopathic intracranial hypertension and associated factors in obese children and adolescents. J Pediatr Endocrinol Metab 2016;29:907-914. 
Bohn et al.: Changing Characteristics of Obese Children and Adolescents Entering Pediatric Lifestyle Intervention Programs in Germany over the Last 11 Years: An

Adiposity Patients Registry Multicenter Analysis of 65,453 Children and Adolescents

-24 Duzova A, Yalcinkaya F, Baskin E, Bakkaloglu A, Soylemezoglu O: Prevalence of hypertension and decreased glomerular filtration rate in obese children: results of a population-based field study. Nephrol Dial Transplant 2013;28(suppl 4):iv166-171.

-25 Flechtner-Mors M, Neuhauser H, Reinehr T, Roost HP, Wiegand S, Siegfried W, Zwiauer K, Molz E, Holl RW: Blood pressure in 57,915 pediatric patients who are overweight or obese based on five reference systems. Am J Cardiol 2015;115:1587-1594.

-26 Jasik CB, King EC, Rhodes E, Sweeney B, Mietus-Snyder M, Grow HM, Harris JM2nd, Lostocco L, Estrada E, Boyle K, Tucker JM, Eneli IU, Woolford SJ, Datto G, Stratbucker W, Kirk S: Characteristics of youth presenting for weight management: Retrospective national data from the POWER study group. Child Obes 2015;11:630-637.

27 Sozialgesetzbuch (SGB) Fünftes Buch: Gesetzliche Krankenversicherung - (Artikel 1 des Gesetzes vom 20. Dezember 1988, BGBl. I S. 2477) § 43 Ergänzende Leistungen zur Rehabilitation, Sozialgesetzbuch (SGB) Fünftes Buch. www.gesetze-im-internet.de/sgb_5/_43.html (last accessed October 5, 2017).

28 Böhler T,Wabitsch M, Winkler U: Konsensuspapier. Patientenschulungsprogramme für Kinder und Jugendliche mit Adipositas, 2004. www.aga.adipositas-gesellschaft.de/index.php?id=388 (last accessed October 5, 2017).

29 Oude LH, Baur L, Jansen H, Shrewsbury VA, O’Malley C, Stolk RP, Summerbell CD: Interventions for treating obesity in children. Cochrane Database Syst Rev 2009;1:CD001872.

-30 Waters E, de Silva-Sanigorski A, Hall BJ, Brown T, Campbell KJ, Gao Y, Armstrong R, Prosser L, Summerbell CD: Interventions for preventing obesity in children. Cochrane Database Syst Rev 2011;1:CD001871.

-31 Muhlig Y, Wabitsch M, Moss A, Hebebrand J: Weight loss in children and adolescents. Dtsch Arztebl Int 2014; 111:818-824.

32 GKV-Spitzenverband: Gemeinsame Empfehlungen zur Förderung und Durchführung von Patientenschulungen für behandlungsbedürftige adipöse Kinder und Jugendliche auf der Grundlage von § 43 Abs. 1 Nr. 2 SGB V vom 2. Dezember 2013 in der Fassung vom 21. April 2015. Bonn, 2015. www.gkv-spitzenverband.de/krankenversicherung/rehabilitation/patientenschulungen/patientenschulungen_1.jsp (last accessed October 5, 2017).

33 Bundesministerium der Justiz und Verbraucherschutz: Sozialgesetzbuch (SGB) Sechstes Buch (VI) - Gesetzliche Rentenversicherung - (Artikel 1 des Gesetzes vom 18. Dezember 1989, BGBl. I S. 2261, 1990 I S. 1337): $\S 31$ Sonstige Leistungen. www.gesetze-im-internet.de/sgb_6/_31.html (last accessed October 5, 2017).

34 Deutsche Rentenversicherung Bund: Anforderungsprofil für eine stationäre Einrichtung zur medizinischen Rehabilitation von Kindern und Jugendlichen. Berlin, 2010. www.deutsche-rentenversicherung.de/Bund/de/ Inhalt/2_Rente_Reha/02_reha/05_fachinformationen/03_infos_fuer_reha_einrichtungen/_downloads/anforderungsprofile/med_reha_kinder_jugend.html (last accessed October 5, 2017).

35 Sweeting HN. Gendered dimensions of obesity in childhood and adolescence. Nutr J 2008;7:1.

36 Hankinson A, Daviglus ML, Loria C, Lewis CE, Liu K. Longer duration of overweight/obesity associated with higher odds of developing hypertension or dyslipidemia: The Coronary Artery Risk Development in Young Adults (CARDIA) Study. Circulation 2010;122:A16208 (abstract). 